\title{
An Approach for Evaluating New Energy Industry Security and Its Application
}

\author{
$\mathrm{Xu}$ Jun \\ Business School \\ Jiangsu Normal University \\ Xuzhou, China \\ 1mmxjxj@163.com
}

\author{
Ren Tengfei* \\ School of Business Administration \\ Henan Polytechnic University \\ Jiaozuo, China \\ rentengfei1993@163.com
}

\begin{abstract}
In order to solve various issues arising from the new energy industry development, effectively avoid the happening of industry crisis, this article firstly constructs an evaluation index system of three layer hierarchical type on the basis of the industry security theory. Then an evaluation approach of the new energy industry security is build based on extension theory and information entropy technology. Finally, an empirical study on the solar energy photovoltaic industry security is conducted and the results are basically consistent with actual situation, which verifies the validity and accuracy of the proposed method. All of these provide a feasible solution for the new energy industry security evaluation.
\end{abstract}

Keywords-New energy industry; Industry security; Evaluation, Extension model

\section{INTRODUCTION}

At present, China is in a critical period of economic and social transformation, resource constraints and environmental issues have become increasingly prominent, the downward pressure on the economy continues to increase, the emergence of new energy industry provides a good opportunity for China's economic restructuring and energy structure optimization. New energy is not only to supplement the traditional energy, but also can effectively control the pollution of the environment, is a new driving force for economic growth. With the strong support of national policy, China's new energy industry has made great achievements in the past ten years, such as the introduction of industrial policy, the continuous expansion of the scale of enterprises and the continuous improvement of technical level. However, the new energy industry implements the quantity accumulation, but the lack of domestic market demand, too high foreign dependence, the lack of core technology are particularly prominent to the healthy development of new energy industry. The reason of these problems in the final analysis is the issue of industrial security. On the one hand, many models have been used in order to evaluate new energy industry, such as responsibility model[1], wavelet neural network model[2],Porter's five forces model[3], option-games approach[4] and so on. On the other hand, as a mature evaluation method, matter-element extension model is widely used, such as risk assessment, water quality evaluation, river health, enterprise innovation capability and so on. The matter-element extension model can be used to evaluate the safety of new energy industry, the study found. In view of this, this paper attempts to build a new energy industry security evaluation index system, the extension analysis method is introduced into the security evaluation of new energy industry, and take the solar photovoltaic industry as an example, finally put forward the policy recommendations.

\section{EVALUATION INDEX SYSTEM OF NEW ENERGY INDUSTRY SECURITY}

Based on the theory of industrial security, in strict accordance with the special nature, scientific, systematic, operability and other indicators to select the principles, and reference to the relevant research results, a new energy industry security evaluation index system is constructed. The index system consists of three layers: first, the target layer, the level of new energy industry security; Second, the criterion layer, including the survival of the new energy industry environment, international competitiveness, sustainable development capacity and dependence on foreign countries, industrial security capabilities in five areas; Third, the index layer, evaluation index of the criterion layer, 27 indices together. Data are listed in table 1.

The index system contains the main influencing factors of new energy industry security. Each index of the criterion layer belongs to the category of industrial security evaluation, compared with other areas of industrial security evaluation index, added two criteria layers, namely, Industry sustainable development ability (B3) and industrial security capability (B5). This is because the new energy industry as a strategic, green industry, the sustainability of its development is a key factor which is different from traditional industry, and this factor has a significant impact on new energy industry security, must be fully reflected in the index system.

\section{EXTENSION MODEL OF NEW ENERGY INDUSTRY SECURITY}

Extenic is an interdisciplinary subject of comprehensive thinking science, system science and mathematics, which is put forward by Cai Wen, a researcher of our country. The main object of extenic is the complex problem, which is suitable for multi factor evaluation. The security of new energy industry is a relatively vague concept, which involves a 
wide range of evaluation indicators, and the single index evaluation results are incompatible. In theory, this method can be used to evaluate the security of new energy industry. The principle and steps of extension model are as follows:

\section{TABLE I. EVALUATION INDEX SYSTEM OF NEW ENERGY} INDUSTRY SECURITY

\begin{tabular}{|c|c|c|}
\hline $\begin{array}{l}\text { Target } \\
\text { layer }\end{array}$ & Criterion layer & Index layer \\
\hline \multirow{27}{*}{$\begin{array}{l}\text { Security } \\
\text { level of } \\
\text { new } \\
\text { energy } \\
\text { industry } \\
\text { (A) }\end{array}$} & \multirow{7}{*}{$\begin{array}{l}\text { Industrial } \\
\text { environment } \\
\text { (B1) }\end{array}$} & Policy and law environment $(\mathrm{C} 1)$ \\
\hline & & Economic operation status (C2) \\
\hline & & Social recognition (C3) \\
\hline & & Market competition environment (C4) \\
\hline & & Capital cost (C5) \\
\hline & & Labor cost (C6) \\
\hline & & Foreign trade environment (C7) \\
\hline & \multirow{6}{*}{$\begin{array}{c}\text { Industrial } \\
\text { international } \\
\text { competitiveness } \\
\text { (B2) }\end{array}$} & Independent innovation ability (C8) \\
\hline & & Scientific and technological level (C9) \\
\hline & & International market share (C10) \\
\hline & & Trade competitiveness index (C11) \\
\hline & & Sales profit margin (C12) \\
\hline & & Industrial concentration (C13) \\
\hline & \multirow{6}{*}{$\begin{array}{c}\text { Industry } \\
\text { sustainable } \\
\text { development } \\
\text { ability (B3) }\end{array}$} & Industrial environmental benefit (C14) \\
\hline & & Domestic market share (C15) \\
\hline & & Industrial structure (C16) \\
\hline & & R\&D intensity (C17) \\
\hline & & Professional personnel proportion (C18) \\
\hline & & The rate of technology transfer (C19) \\
\hline & \multirow{4}{*}{$\begin{array}{l}\text { Industrial } \\
\text { external } \\
\text { dependence } \\
\text { (B4) }\end{array}$} & Import dependence ratio (C20) \\
\hline & & Export dependence ratio $(\mathrm{C} 21)$ \\
\hline & & Foreign dependence of capital (C22) \\
\hline & & Foreign dependence of technology (C23) \\
\hline & \multirow{4}{*}{$\begin{array}{c}\text { Industrial } \\
\text { security } \\
\text { capability (B5) }\end{array}$} & Organizational construction level (C24) \\
\hline & & $\begin{array}{l}\text { Improvement of early warning mechanism } \\
\text { (C25) }\end{array}$ \\
\hline & & Crisis response ability (C26) \\
\hline & & Legal guarantee level (C27) \\
\hline
\end{tabular}

\section{EXTENSION MODEL OF NEW ENERGY INDUSTRY SECURITY}

Extenic is an interdisciplinary subject of comprehensive thinking science, system science and mathematics, which is put forward by Cai Wen, a researcher of our country. The main object of extenic is the complex problem, which is suitable for multi factor evaluation. The security of new energy industry is a relatively vague concept, which involves a wide range of evaluation indicators, and the single index evaluation results are incompatible. In theory, this method can be used to evaluate the security of new energy industry. The principle and steps of extension model are as follows:

\section{A. Step 1: Determine the Classical Field}

Assuming that the research object has $\mathrm{n}$, and it is divided into $\mathrm{m}$ safety levels, $N_{f}(f=1,2, \cdots, \mathrm{m})$ indicates level $f, C_{i}(i=$ $1,2, \cdots, n)$ is a feature of the security level $N_{f}, V_{f i}=\left\langle a_{f i}, b_{f i}\right\rangle$ is the corresponding range of values for the level $f\left(N_{f}\right)$, the classical field is as follows:

$$
R_{\mathrm{j}}=\left[\begin{array}{ccc}
N_{j} & C_{1} & V_{j 1} \\
& C_{2} & V_{j 2} \\
& \vdots & \vdots \\
& C_{\mathrm{n}} & V_{j n}
\end{array}\right]=\left[\begin{array}{ccc}
N & C_{1} & <a_{j 1}, b_{j 1}> \\
& C_{2} & <a_{j 2}, b_{j 2}> \\
& \vdots & \vdots \\
& C_{n} & <a_{j n}, b_{j n}>
\end{array}\right]
$$

\section{B. Step 2: Determine the Segment Field}

Using $P$ to represent the overall safety level of the new energy industry, $V_{p i}=\left\langle a_{p i}, b_{p i}\right\rangle, V_{p i}$ is the range of all possible values of $C_{i}$, so, the segment field matter elements of new energy industry security is as follows:

$$
R_{\mathrm{P}}=\left[\begin{array}{ccc}
P & C_{1} & V_{P 1} \\
& C_{2} & V_{P 2} \\
& \vdots & \vdots \\
& C_{\mathrm{n}} & V_{P}
\end{array}\right]=\left[\begin{array}{ccc}
P & C_{1} & <a_{P 1}, b_{P 1}> \\
& C_{2} & <a_{P 2}, b_{P 2}> \\
\vdots & \vdots \\
& C_{n} & <a_{P n}, b_{P n}>
\end{array}\right]
$$

\section{Step 3: Determine the Matter-element Evaluation}

The collected data is expressed by the matter element $\mathrm{R}$, among them, $V_{i}$ is the specific value of each index. New energy industry security for matter-element evaluation can be expressed as:

$$
R=\left[\begin{array}{ccc}
N & C_{1} & V_{1} \\
& C_{2} & V_{2} \\
& \cdots & \cdots \\
& C_{\mathrm{n}} & V_{n}
\end{array}\right]
$$

\section{Step 4: Weight Determination}

In this paper, the analytic hierarchy process (AHP) is used to weight the index, the judgment matrix is constructed by $9 / 9$ 9/1 scale method, and the weights are corrected by entropy technique in order to increase the amount of information, improve the credibility of the evaluation results. The final weight $\lambda_{j}$ is calculated as:

$$
\lambda_{j}=\frac{\mu_{j} \omega_{j}}{\sum_{j=1}^{n} \mu_{j} \omega_{j}}
$$


Among them, $\lambda_{j}$ is the index weight, $\omega_{j}$ refers to the AHP index weight, $\mu_{j}$ refers to the information entropy weight of index $a_{j}$.

\section{E. Step 5: Calculate the Correlation Degree}

Correlation degree is a quantitative tool that can describe the relationship between objects. The degree of correlation is used to represent the degree of correlation between matterelement evaluation and the evaluation grade. $K_{f}\left(V_{i}\right)$ is the correlation of the index $i$ about the level $f$.

The formula is as follows:

$$
K_{f}\left(V_{i}\right)=\left\{\begin{array}{l}
\frac{-\rho\left(v_{i}, V_{f i}\right)}{Z_{j i}}, \quad v_{i} \in V_{f i} \\
\frac{\rho\left(v_{i}, V_{f i}\right)}{\rho\left(V_{i}, V_{p i}\right)-\rho\left(V_{i}, V_{f i}\right)}, \quad v_{i} \notin V_{f i}
\end{array}\right.
$$

among them, $\quad \rho\left(v_{i}, V_{f i}\right)=\left|v_{i}-\frac{a_{f i}+b_{f i}}{2}\right|-\frac{b_{f i}-a_{f i}}{2}$

$$
\begin{aligned}
& \rho\left(v_{i}, V_{p i}\right)=\left|v_{i}-\frac{a_{p i}+b_{p i}}{2}\right|-\frac{b_{p i}-a_{p i}}{2} \\
& \boldsymbol{Z}_{f i}=\left|\boldsymbol{a}_{f i}-\boldsymbol{b}_{f i}\right|
\end{aligned}
$$

\section{F. Step 6: Determine Grade}

First, the correlation degree of each criterion layer $B_{i}$ of new energy industry security about grade $f$ as:

$$
K_{f}\left(B_{i}\right)=\sum_{l=1}^{n} \alpha_{i l} K_{f}\left(V_{i l}\right)
$$

Among them, $\alpha_{i l}$ refers to entropy correction weight which belong to the subordinate indicators of criterion layer $B_{i}, V_{i l}$ is the value of subordinate index of criterion layer $B_{i}$, using the principle of maximum degree of membership to judge the grade of $B_{i}$, if $K_{f}\left(B_{i}\right)=\max \left\{K_{f}\left(B_{i}\right)\right\}$, then the level of $B_{i}$ is $f$.

Second, The formula for calculating the comprehensive correlation degree of the new energy industry is as follows:

$$
K_{f}(A)=\sum_{i=1}^{n} \lambda_{i} K_{f}\left(B_{i}\right)
$$

$\lambda_{i}$ corresponds to the weight of $B_{i}$, if $K_{f}(A)=\max \left\{K_{f}(A)\right\}$, the level of the new energy industry security belongs to $f$.

When $K_{f}(R) \geq 0$, the results show that the evaluation object meets the requirements of the standard level, the greater the value, the better the degree of conformity with the grade.

When $K_{f}(R)<-1$, indicates that the evaluation object does not meet the requirements of the standard level, and does not have the conditions to be transformed into the standard grade.

When $-1 \leq K_{f}(R)<0$, the results show that the evaluation unit belongs to a certain level under the principle of maximum membership, but it does not meet the requirements of the standard grade, however, with the transformation into the standard level conditions, the greater the value, the easier the transformation.

\section{APPLICATION EXAMPLE}

Present stage, China's new energy sources, including wind energy, solar energy, nuclear energy, biomass, etc., among them, the degree of industrialization of wind energy and solar energy is relatively high, they occupy an important seat in the new energy. In particular, the solar photovoltaic industry has developed rapidly in recent years, but the problems are also particularly prominent. Solar photovoltaic industry is a typical representative of China's new energy industry, in this paper, the photovoltaic industry as an example.

\section{A. Determine the Weights of Indexes}

AHP method is used to determine the weights, and according to the entropy method to modify the weights of the steps, the final weight of the criteria layer is as follows:

$$
\lambda_{i}=(0.1942,0.2370,0.2096,0.1942,0.1650)^{\mathrm{T}},(\mathrm{i}=1,2, \ldots, 5)
$$

The final weight of each index layer:



\section{B. Data acquisition and Classification}

Photovoltaic industry is a new industry in our country, and there are few data about its industrial security. On the basis of fully complying with the scientific nature, the index value should be calculated as far as possible. The required data are required from BP world energy statistics yearbook 2013. For qualitative indicators and quantitative indicators which are difficult to obtain accurately, the first-hand data were obtained through expert survey. The domestic and foreign research indicated that the expert survey method is a scientific forecast method, its purpose is to make a reasonable estimation of the factors which are difficult to adopt the method of quantitative analysis, which is suitable for the situation that the data is not sufficient and the theory is not perfect. In this paper, the indexes are divided into five grades: better (higher), good (high), general, poor (low) and worse (lower), the corresponding scoring range of each grade are: 80-100, 60-80, $40-60,20-40,0-20$. Based on the actual situation of the development of photovoltaic industry, the relevant experts to make judgments, with a certain degree of objectivity. The research on the security evaluation of new energy industry is not mature, and there is no uniform standard. This paper refers to the research of Li Menggang, a senior scholar in the field of industrial security, and Liu Daoxin's classification of industrial security standards, its industrial security is divided into five levels: secure N1, relatively secure $\mathrm{N} 2$, basically secure N3, less secure N4, insecure N5. 


\section{Evaluation Process}

1) Industrial environment (B1) evaluation

First, the values of the classical fields $R_{B 11}, R_{B 12}, R_{B 13}, R_{B 14}$, $R_{B 15}$, and segment field $R_{B 1 P}$ are as follows:

$$
\begin{aligned}
& R_{B 11}=\left[\begin{array}{ccc}
N 1 & c_{1} & <85,100> \\
& c_{2} & <85,100> \\
& c_{3} & <85,100> \\
& c_{4} & <80,100> \\
& c_{5} & <0,5.5> \\
& c_{6} & <80,100> \\
& c_{7} & <80,100>
\end{array}\right] \quad R_{\mathrm{B} 12}=\left[\begin{array}{ccc}
N 2 & c_{1} & <70,85> \\
& c_{2} & <70,85> \\
& c_{3} & <70,85> \\
& c_{4} & <60,80> \\
& c_{5} & <5.5,6.5> \\
& c_{6} & <60,80> \\
& c_{7} & <60,80>
\end{array}\right] \\
& R_{B 13}=\left[\begin{array}{ccc}
N 3 & c_{1} & <50,70> \\
& c_{2} & <50,70> \\
& c_{3} & <50,70> \\
& c_{4} & <40,60> \\
& c_{5} & <6.5,7.5> \\
& c_{6} & <40,60> \\
& c_{7} & <40,60>
\end{array}\right] \quad R_{B 14}=\left[\begin{array}{ccc}
N 4 & c_{1} & <30,50> \\
& c_{2} & <30,50> \\
& c_{3} & <30,50> \\
& c_{4} & <20,40> \\
& c_{5} & <7.5,10> \\
& c_{6} & <20,40> \\
& c_{7} & <20,40>
\end{array}\right] \\
& R_{B 15}=\left[\begin{array}{ccc}
N 5 & c_{1} & <0,30> \\
& c_{2} & <0,30> \\
& c_{3} & <0,30> \\
& c_{4} & <0,20> \\
& c_{5} & <10,20> \\
& c_{6} & <0,20> \\
& c_{7} & <0,20>
\end{array}\right] \quad R_{B 1 P}=\left[\begin{array}{ccc}
N & c_{1} & <0,100> \\
& c_{2} & <0,100> \\
& c_{3} & <0,100> \\
& c_{4} & <0,100> \\
& c_{5} & <0,20> \\
& c_{6} & <0,100> \\
& c_{7} & <0,100>
\end{array}\right]
\end{aligned}
$$

Second, the matter-element evaluation $R_{B 1}$ are as follows:

$$
R_{\mathrm{B} 1}=\left[\begin{array}{ccc}
B 1 & c_{1} & 68 \\
& c_{2} & 65 \\
& c_{3} & 55 \\
& c_{4} & 32 \\
& c_{5} & 6.0 \\
& c_{6} & 70 \\
& c_{7} & 36
\end{array}\right]
$$

Third, the correlation degree of each index is calculated by formula (3), and the results are shown in table 2 (line C1-C7).

Fourth, determine the grade of matter-element evaluation, according to the formula (4), the comprehensive membership degree of the living environment criterion layer is obtained:

$$
\begin{aligned}
& K_{\mathrm{j}}(B 1)=[-0.376,-0.067,0.006,-0.125,-0.433] \\
& K(B 1)=\max K_{j}(B 1)=K_{N 3}(B 1)=0.006
\end{aligned}
$$

Thus, the judgment of China's photovoltaic industry living environment at N3 level, " basically secure ".

\section{2) Other criterion layer security rating}

Using the same method, the evaluation results of industrial international competitiveness (B2), industrial sustainable development capability (B3), industrial external dependence (B4) and industrial security capability (B5) were obtained. The evaluation results of each index layer are shown in table 2

3) Comprehensive evaluation and result analysis

According to the formula (4), the comprehensive correlation degree of photovoltaic industry security is calculated by weighting method:

$$
K_{f}(A)=[-0.4411,-0.2699,-0.1045,0.0510,-0.3125]
$$

\begin{tabular}{|c|c|c|c|c|c|c|c|}
\hline Index & N1 & N2 & N3 & N4 & N5 & $\operatorname{maxK}_{f}\left(\mathbf{V}_{i}\right)$ & $\begin{array}{c}\text { Evaluation } \\
\text { results }\end{array}$ \\
\hline $\mathrm{C} 1$ & -0.347 & -0.059 & 0.100 & -0.360 & -0.543 & 0.100 & $\begin{array}{c}\text { Basically } \\
\text { secure }\end{array}$ \\
\hline $\mathrm{C} 2$ & -0.364 & -0.125 & 0.250 & -0.300 & -0.500 & 0.250 & $\begin{array}{c}\text { Basically } \\
\text { secure }\end{array}$ \\
\hline $\mathrm{C} 3$ & -0.400 & -0.250 & 0.250 & -0.100 & -0.357 & 0.250 & $\begin{array}{c}\text { Basically } \\
\text { secure }\end{array}$ \\
\hline $\mathrm{C} 4$ & -0.600 & -0.467 & -0.200 & 0.400 & -0.273 & 0.400 & Less secure \\
\hline C5 & -0.077 & 0.500 & -0.077 & -0.200 & -0.400 & 0.500 & $\begin{array}{c}\text { Relatively } \\
\text { secure }\end{array}$ \\
\hline C6 & -0.250 & 0.500 & -0.250 & -0.500 & -0.625 & 0.500 & $\begin{array}{c}\text { Relatively } \\
\text { secure }\end{array}$ \\
\hline $\mathrm{C} 7$ & -0.550 & -0.400 & -0.100 & 0.200 & -0.308 & 0.200 & Less secure \\
\hline $\mathrm{C} 8$ & -0.563 & -0.417 & -0.125 & 0.250 & -0.300 & 0.250 & Less secure \\
\hline C9 & -0.375 & -0.167 & 0.500 & -0.167 & -0.375 & 0.500 & $\begin{array}{c}\text { Basically } \\
\text { secure }\end{array}$ \\
\hline $\mathrm{C} 10$ & 0.370 & -0.370 & -0.460 & -0.528 & -0.580 & 0.370 & Secure \\
\hline $\mathrm{C} 11$ & -0.100 & 0.167 & -0.357 & -0.550 & -0.654 & 0.167 & $\begin{array}{c}\text { Relatively } \\
\text { secure }\end{array}$ \\
\hline $\mathrm{C} 12$ & -0.588 & -0.450 & -0.175 & 0.350 & -0.283 & 0.350 & Less secure \\
\hline $\mathrm{C} 13$ & -0.280 & 0.365 & -0.183 & -0.455 & -0.591 & 0.365 & $\begin{array}{c}\text { Relatively } \\
\text { secure }\end{array}$ \\
\hline $\mathrm{C} 14$ & -0.368 & -0.143 & 0.200 & -0.400 & -0.600 & 0.200 & $\begin{array}{c}\text { Basically } \\
\text { secure }\end{array}$ \\
\hline $\mathrm{C} 15$ & -0.625 & -0.500 & -0.250 & 0.500 & -0.250 & 0.500 & Less secure \\
\hline $\mathrm{C} 16$ & -0.525 & -0.367 & -0.050 & 0.100 & -0.321 & 0.100 & Less secure \\
\hline $\mathrm{C} 17$ & -0.488 & -0.317 & 0.050 & -0.024 & -0.339 & 0.050 & $\begin{array}{c}\text { Basically } \\
\text { secure }\end{array}$ \\
\hline $\mathrm{C} 18$ & -0.563 & -0.417 & -0.125 & 0.250 & -0.300 & 0.250 & Less secure \\
\hline $\mathrm{C} 19$ & -0.368 & -0.143 & 0.400 & -0.200 & -0.400 & 0.400 & $\begin{array}{c}\text { Basically } \\
\text { secure }\end{array}$ \\
\hline $\mathrm{C} 20$ & -0.575 & -0.433 & -0.150 & 0.300 & -0.292 & 0.300 & $\begin{array}{l}\text { Basically } \\
\text { secure }\end{array}$ \\
\hline $\mathrm{C} 21$ & -0.597 & -0.546 & -0.395 & -0.093 & 0.093 & 0.093 & Insecure \\
\hline $\mathrm{C} 22$ & -0.300 & 0.250 & -0.125 & -0.147 & -0.300 & 0.250 & $\begin{array}{c}\text { Relatively } \\
\text { secure }\end{array}$ \\
\hline $\mathrm{C} 23$ & -0.706 & -0.643 & -0.500 & -0.167 & 0.167 & 0.167 & Insecure \\
\hline $\mathrm{C} 24$ & -0.375 & -0.167 & 0.500 & -0.167 & -0.375 & 0.500 & $\begin{array}{l}\text { Basically } \\
\text { secure }\end{array}$ \\
\hline $\mathrm{C} 25$ & -0.671 & -0.600 & -0.440 & -0.067 & 0.067 & 0.067 & Insecure \\
\hline $\mathrm{C} 26$ & -0.538 & -0.383 & -0.075 & 0.150 & -0.315 & 0.150 & Less secure \\
\hline $\mathrm{C} 27$ & -0.563 & -0.417 & -0.125 & 0.250 & -0.300 & 0.250 & Less secure \\
\hline
\end{tabular}

$$
K_{f}(A)=\max \left\{K_{f}(A)\right\}=K_{N 4}(A)=-0.0510
$$

According to the principle of maximum membership, China's solar photovoltaic industry is at N4 level, "less secure", specific evaluation results are shown in table 3

TABLE II. EVALUATION RESULTS OF PV INDUSTRY SECURITY INDICATORS 
TABLE III. COMPREHENSIVE EVALUATION RESULTS OF PHOTOVOLTAIC INDUSTRY SECURITY

\begin{tabular}{|c|c|c|c|c|c|c|c|}
\hline Evaluation objects & $\mathbf{N 1}$ & $\mathbf{N 2}$ & $\mathbf{N 3}$ & $\mathbf{N 4}$ & $\mathbf{N 5}$ & $\operatorname{maxK}_{\mathbf{f}}(\mathbf{R})$ & Evaluation results $^{-1}$ \\
\hline Photovoltaic industry (A) & -0.4411 & -0.2699 & -0.1045 & -0.0510 & -0.3125 & -0.0510 & Less secure \\
\hline Industrial environment (B1) & -0.3764 & -0.0671 & 0.0056 & -0.1254 & -0.4330 & 0.0056 & Basically secure \\
\hline Industrial international competitiveness (B2) & -0.2561 & -0.1656 & -0.1586 & -0.1664 & -0.4597 & -0.1586 & Basically secure \\
\hline Industry sustainable development ability (B3) & -0.4933 & -0.3195 & 0.0314 & 0.0506 & -0.3629 & 0.0314 & Less secure \\
\hline Industrial external dependence (B4) & -0.5860 & -0.4308 & -0.3279 & -0.0249 & -0.0409 & -0.0249 & Less secure \\
\hline Industrial security capability (B5) & -0.5462 & -0.4062 & -0.0659 & 0.0424 & -0.2150 & 0.0424 & Less secure \\
\hline
\end{tabular}

From the extension model to evaluate the security of photovoltaic industry, China's photovoltaic industry is in poor condition, in a state of "less secure". Objectively speaking, this result is in line with the actual development of photovoltaic industry. Through the analysis, the relationship between China's photovoltaic industry security and N4 ("less secure") is the largest, but the correlation is negative, indicating that there is a certain gap between the level of photovoltaic industry security and N4. The reason is that the ability of sustainable development of photovoltaic industry is not strong, the lack of protection of industrial security, foreign dependence is too high and so on, at the same time, it also has some connection with the international competitiveness of the industry and the living environment.

\section{Countermeasures and Suggestions}

Firstly, improve the industrial environment. To respect the market, give full play to the decisive role of market allocation of resources, policies and regulations should be based on market rules, as far as possible to avoid blind intervention, reduce dependence on the industry policy. It is necessary to develop a strong forward-looking and operational industrial policy, with particular emphasis on the development of the application market, in order to create a good environment for industrial development and foreign trade. In addition, improve relevant laws and regulations, establish the market access system and regulatory mechanisms, and regulate the industry competitive environment.

Secondly, further enhance international competitiveness. Competitive ability is the core content of photovoltaic industry security, the evaluation results of the international competitiveness of China's photovoltaic industry is the "basically secure", which support mainly comes from the international market share, foreign trade competitiveness index and industrial concentration index. However, the ability of independent innovation is weak, and the profit level is low, which greatly weakened the international competitiveness. Therefore, it is necessary to strengthen the ability of independent innovation of the industry, and make a major breakthrough in product, technology, management and so on, and then reduce costs, improve the level of profits.

Thirdly, gradually reduce the external dependence of photovoltaic industry. China's photovoltaic industry is weak, technology, exports and other aspects of high dependence on foreign. To solve the technical problems, we should increase the investment of capital and talents, and carry out technical innovation. Vigorously develop the domestic market, solve the export problem, and actively explore a wide range of international markets, avoid a high dependence on a country, reduce the operating risk in the international market.

Fourthly, focus on enhancing industrial security capabilities. Strengthen the construction of industrial security organization, build a special security sector for strategic emerging industries, which is composed of industry associations, industrial security research institutions, etc., and set up branches to safeguard the safety of photovoltaic industry. Moreover, improve security evaluation mechanism and early warning mechanism for photovoltaic industry, establish photovoltaic industry security database based on information technology, set up electronic platform to collect and distribute industrial security information. Meanwhile, improve the effectiveness of information communication between government, industry associations and enterprises, and form a long-term mechanism of industrial security maintenance.

\section{CONCLUSION}

In this paper, the security evaluation index system and extension evaluation model of new energy industry are constructed, the applicability and effectiveness of the extension method are verified in the security evaluation of solar photovoltaic industry, and the evaluation results accord with the actual situation of photovoltaic industry development, which has some reference value for the evaluation of the strategic emerging industries.

\section{REFERENCES}

[1] Q Wang and X Guo. "Countermeasure and interaction of common technoinnovation and new energy industry development," Energy Procedia, vol. 5, pp. 1308-1312, 2011.

[2] S Yang, Q Zhu, and Z Liu. "The comprehensive evaluation of new energy industry developing capability based on wavelet neural network model," Journal of Computers, vol. 7, pp. 439-443, 2012.

[3] J Zhang and Y Zhang. "Analysis on current situation and the competitiveness of new energy industry in Tianjin," Science \& Technology Management Research, vol. 33, pp. 1476-1481, 2014.

[4] N N Aye and T Fujiwara. "Application of option-games approach to the irreversible investment for a new energy industry in myanmar by simple one-stage strategic model: focused on potential of smart house," Global Journal of Flexible Systems Management, vol. 15, pp. 191-202, September 2014. 